\title{
A Friendly Article: The Qualitative Investigation of Anthropomorphism in Autistic and Nonautistic Adults
}

\author{
Orli Negri, MSc, Rebekah C. White, $\mathrm{PhD}{ }^{2}$ and Anna Remington, $\mathrm{PhD}^{1}$
}

\begin{abstract}
Background: Anthropomorphism is the attribution of human characteristics to nonhuman agents. This common tendency is thought to be driven by a heightened motivation for social connection and may therefore be expected to be reduced in autistic individuals given that this group has been claimed to demonstrate reduced social motivation in some settings. However, the subject of anthropomorphism in autism has not been studied extensively, and online forums, autobiographical accounts, and recent research on the topic suggest that, contrary to this expectation, anthropomorphism is commonly experienced by autistic individuals.

Methods: We conducted semi-structured interviews with eight autistic and eight nonautistic adults, all who reported a tendency to anthropomorphize. We recorded, transcribed, and analyzed the interviews according to the thematic analysis framework with the objective of identifying similarities and differences in the lived experiences of anthropomorphism in autistic and nonautistic individuals.

Results: Individuals in both groups described anthropomorphism as comforting, promoting a sense of safety and friendship with, and feelings of empathy and sympathy toward, nonhuman agents. Autistic individuals stressed the important role anthropomorphized agents played in their life, particularly when growing up: easing loneliness and helping develop an understanding of emotions and relationships. Participants also expressed negative aspects of the phenomenon, with both autistic and nonautistic individuals worrying about anthropomorphized agents' feelings and well-being. For some individuals, such thoughts and feelings caused distress and were experienced as intrusive due to their involuntary nature.

Conclusions: Autistic and nonautistic adults showed very similar anthropomorphic patterns. Although preliminary in nature, our findings highlight characteristics of anthropomorphic experiences for autistic and nonautistic individuals, furthering our understanding of individual differences in social cognition. By illustrating the important role nonhuman agents may play in the lives of autistic individuals, our findings may also guide future research and practice.
\end{abstract}

Keywords: anthropomorphism, autism, social cognition, social motivation

\section{Lay Summary}

Why was this study done?

'Anthropomorphism' is when you feel that non-human items have human characteristics, for example if you experience plants, animals, or household objects as having thoughts or feelings. Anthropomorphism is experienced by many people in many different ways. Researchers think it might happen when people have a strong desire for social connection. This has led some to suggest that autistic people will be less likely to anthropomorphise due to difficulties in social understanding and motivation. However, researchers have not examined this directly, and our prior research, together with comments in online forums and autobiographical accounts, indicated that autistic individuals may experience a special relationship with non-human items.

\footnotetext{
${ }^{1}$ Centre for Research in Autism and Education (CRAE), UCL Institute of Education, London, United Kingdom.

${ }^{2}$ Department of Experimental Psychology, University of Oxford, Oxford, United Kingdom.
} 
What was the purpose of this study?

The purpose of the study was to speak directly to people who anthropomorphise and hear about their experiences. We could then compare patterns of anthropomorphism between autistic and non-autistic adults.

\section{What did the researchers do?}

We interviewed 16 adults ( 8 autistic and 8 non-autistic) who told us they anthropomorphised, and asked about their personal experiences of anthropomorphism.

\section{What were the results of the study?}

Autistic and non-autistic adults described very similar experiences of anthropomorphism. People in both groups described anthropomorphism as comforting, and said that it gave them a sense of safety and friendship. They also cared for, and experienced feelings of empathy toward, anthropomorphised items. Individuals in both groups worried about anthropomorphised items' feelings and well-being and this caused some people considerable distress. Autistic individuals stressed the important role anthropomorphised items played in their life, particularly when growing up: reducing loneliness and helping them develop an understanding of emotions and relationships.

What do these findings add to what was already known?

Our findings show that there are many similarities in the experiences of anthropomorphism in autistic and nonautistic adults. The findings also show how, for some autistic adults, anthropomorphism was helpful in developing relationships with other people.

\section{What are potential weaknesses in the study?}

The small number of participants means that we do not know whether the findings would apply to all people who experience anthropomorphism.

\section{How will these findings help autistic adults now or in the future?}

By showing the various ways in which autistic individuals attach social meanings (such as feelings of caring or friendship) to anthropomorphised items, our findings add to a growing number of studies which challenge the commonly-held assumption that autistic individuals are less motivated to make social connections. Our work shows that autistic individuals may be highly motivated to connect socially, and that meaningful social connections and expressions of empathy need not be limited to human beings.

\section{Introduction}

A NTHROPOMORPHISM IS DEFINED as the attribution of human characteristics (including emotions, intentions, and behavior) to nonhuman subjects, such as animals, plants, or inanimate household objects. Common examples of anthropomorphic experiences may be feeling that a certain tree is friendlier than another or that a computer is malfunctioning intentionally. Although it is considered to be a common phenomenon with vast and various expressions throughout human culture, the tendency to anthropomorphize seems to vary considerably from one person to another. ${ }^{1}$ Our recent research has suggested that one population who may experience increased anthropomorphism are those on the autistic spectrum. A survey of 87 autistic and 263 nonautistic adults in the United Kingdom revealed that anthropomorphism was reported more commonly among autistic individuals, and perhaps more often (and continuing later in life) than in the general population. ${ }^{2}$ Furthermore, various descriptions from autistic individuals on internet blogs and forums, as well as some autobiographical accounts, seem to elaborately describe the perceived mental states of nonhuman agents and include detailed expressions of empathy toward the agents. ${ }^{3-6}$ (Note: since anthropomorphism leads to perceiving nonhuman entities as having agency, anthropomorphized entities are referred to as "agents" within the literature.)

These observations may be interesting, when considering the core characteristics of autism outlined by prevailing theoretical accounts. Autism is a neurodevelopmental condition characterized by differences in social communication, repetitive and restricted interests and behavior, and a hyperor hyposensitive sensory profile. ${ }^{7}$ Mentalizing - the ability to understand and attribute mental states to others-is thought to be challenging for those on the autistic spectrum. ${ }^{8-10} \mathrm{Re}$ cently, research has suggested that this difficulty stems from reduced social motivation, rather than an inability to make inferences about others. ${ }^{11}$ Given that literature also proposed that anthropomorphism exemplifies an increased motivation for reasoning about the minds of others, ${ }^{12,13}$ the observation of increased rates of anthropomorphism for autistic people initially appears counterintuitive.

However, a closer investigation highlights a number of factors that may underpin anthropomorphism in autistic individuals. For example, increased levels of loneliness 
have been reported by individuals on the autistic spectrum compared with nonautistic individuals, ${ }^{14-16}$ and intolerance of uncertainty has been suggested as a significant construct in autism. ${ }^{17-19}$ Both these issues have been linked to the attribution of human characteristics to nonhuman agents: research by Epley et al. ${ }^{12}$ suggested that in nonautistic adults there is an increased tendency to anthropomorphize among those who feel socially isolated or experience a desire for control and predictability. Furthermore, a recent review suggested anthropomorphic tendencies among autistic individuals may be motivated by the considerable difference in the complexity of interaction with humans compared with nonhuman agents. ${ }^{20}$

An alternative account is that, for autistic people, anthropomorphism may be linked to synesthesia (a condition in which certain stimuli trigger unusual, automatic, and involuntary sensations). Recently, subtypes of social synesthesia are identified, in which individuals attribute gender, feelings, and personality traits to graphemes and/or inanimate objects, in a manner that is consistent over time. ${ }^{21-23}$ Anthropomorphism and the various subtypes of social synesthesia are thought to activate brain regions that are linked to the mentalizing network. ${ }^{24,25}$ The observation of higher levels of anthropomorphism in autistic individuals compared with nonautistic individuals ${ }^{2}$ indicates value in revisiting the nature of the mentalizing difficulties within the condition and makes the association of autism and anthropomorphism even more intriguing. Importantly, however, although rates of synesthesia are higher in the autistic community compared with the general population, ${ }^{26,27}$ this is true only of autistic individuals with prodigious talent, ${ }^{28}$ which renders an explanation for high rates of anthropomorphism in autism as being tied to synesthesia less probable.

The potential links between autism and anthropomorphism, Discussed in the Introduction, raise the question as to whether the phenomenon plays a different role, or is different in nature, for autistic people compared with nonautistic people. One way to explore this question is by examining the lived experiences of autistic and nonautistic individuals who anthropomorphize. To date, there has been minimal research on this topic, and indeed, even the literature on anthropomorphism in the general population has yet to explore the first-hand experiences of individuals who report increased anthropomorphic tendencies. The current study provides, to our knowledge, the first qualitative investigation of individual experiences of anthropomorphism in autistic and nonautistic adults, so as to illustrate and compare their personal experiences and provide insight into this interesting mechanism of social cognition.

The importance of this is underlined by the fact that, in online forums, many first-hand accounts by autistic individuals highlight the involuntary nature of anthropomorphism and include negative sentiments, such as feeling guilty about selling an old car that might feel abandoned. ${ }^{6}$ As such, it is necessary to establish whether anthropomorphism plays a different role for autistic and nonautistic individuals, and how best to support those who experience distressing aspects of the phenomenon. Due to limited research on the subject, we chose to use a qualitative approach. First-person perspectives will facilitate a deeper understanding of anthropomorphism, highlighting differences and similarities in the two groups.

\section{Methods}

\section{Participants}

Sixteen participants took part: 8 adults with a selfreported formal diagnosis of autism (4 females and 4 males, aged $21-58$ years, $M=35$ ), and 8 nonautistic adults ( 4 females and 4 males, aged $24-70$ years, $M=40$ ). To maintain anonymity, participants in the autistic and nonautistic groups will be referred to as A1-A8 and N9-N16, respectively. Participants in both groups were recruited from a previous study on anthropomorphism, ${ }^{2}$ online blogs, or a research recruiting website, and all self-reported a regular tendency to anthropomorphize various types of nonhuman agents from a range of categories (e.g., plants, animals, electrical devices, household objects). Two participants (nonautistic group) were from the United States. All other participants were from various locations across the United Kingdom. English was confirmed to be the first language of all participants, thereby reducing the likelihood of linguistic factors, such as gendered nouns, affecting anthropomorphic tendencies. Three participants (A3, A8, and N11) reported a diagnosis of obsessive-compulsive disorder (OCD) or anxiety in childhood and/or adulthood; one of whom (A8) also reported a diagnosis of depression. In addition, two participants in the nonautistic group (N9 and N16) reported grapheme-color synesthesia. Participants in both groups had various educational backgrounds, ranging from high school education to PhD.

Ethical approval for this study was obtained from the Department of Psychology and Human Development Ethics Committee at the University College London Institute of Education, as part of an MSc dissertation. All participants gave informed consent before the start of the interviews.

\section{Procedure}

We conducted semi-structured interviews with participants over the phone $(n=15)$ or in person $(n=1)$ as per the participant's preference. Interviews lasted 20-50 minutes and were audio recorded by the researcher. At the beginning of the interview, the interviewer repeated a definition of anthropomorphism, which had been given to participants as part of the recruiting process. The interview schedule comprised open-ended questions about personal experiences of anthropomorphism, relating to childhood and adulthood. Some questions encouraged general reflection, such as "How do you feel about anthropomorphizing?', while others aimed to elicit descriptions of experiences, such as "Can you describe a certain anthropomorphized agent from your personal experience?" Additional questions aimed to evaluate the stability and consistency of anthropomorphism, by assessing factors that may influence the tendency to anthropomorphize, such as "Do you find that anthropomorphizing is related to your mood?" The interviewer asked all questions in their original phrasing and rephrased with added explanation where participants expressed uncertainty with regard to what was being asked. Anecdotal observations suggested no systematic differences between the groups in requests for rephrasing.

The researcher later transcribed and analyzed the recordings according to a thematic analysis framework, guided by 


\begin{tabular}{|c|c|c|c|}
\hline \multirow[b]{2}{*}{ Themes } & \multirow[b]{2}{*}{ Subthemes } & \multicolumn{2}{|c|}{ Example quotes } \\
\hline & & Autistic & Nonautistic \\
\hline \multirow[t]{3}{*}{$\begin{array}{l}\text { Overall feelings } \\
\quad \text { toward } \\
\text { anthropomorphizing }\end{array}$} & & $\begin{array}{l}\text { "It's just something I do, I don't attach } \\
\text { a particular connotation to it.", (A1) }\end{array}$ & $\begin{array}{l}\text { "I think it's just there, a part of how my } \\
\text { brain sees things. I don't think it's a } \\
\text { bad thing or a good thing." (N14) }\end{array}$ \\
\hline & & $\begin{array}{l}\text { "I think that it's amusing, it's fun. For } \\
\text { example, if the teddy bear is in the } \\
\text { room and I'm alone in my flat, I } \\
\text { don't feel like I'm alone because the } \\
\text { teddy bear is there." (A2) }\end{array}$ & $\begin{array}{l}\text { "I think it's something that I enjoy, I } \\
\text { think it adds richness to my } \\
\text { perception of the things I see and } \\
\text { how I feel about them. The } \\
\text { personification overall is pleasant for } \\
\text { me, and I am grateful for it." (N16) }\end{array}$ \\
\hline & & $\begin{array}{l}\text { "I'd say it's more negative than } \\
\text { positive, because it's as if in my } \\
\text { mind I know that it's not rational } \\
\text { and it's just not needed, but it's as if } \\
\text { I just can't help it." (A3) }\end{array}$ & $\begin{array}{l}\text { "It normally manifest itself in terms of } \\
\text { feeling guilty or bad about things } \\
\text { maybe not being used or abandoned } \\
\text { or lost, that kind of thing, so it would } \\
\text { normally only affect me in a } \\
\text { negative way." (N12) }\end{array}$ \\
\hline \multirow[t]{2}{*}{$\begin{array}{l}\text { Anthropomorphism } \\
\text { as a comforting } \\
\quad \text { experience }\end{array}$} & & $\begin{array}{l}\text { "It could be a variety of things, it } \\
\text { could be a very tactile object, like a } \\
\text { pencil or a pen, just like a } \\
\text { comforting companion, that's what } \\
\text { they became. It's like I thought this } \\
\text { pencil is my friend and I'm going to } \\
\text { look after it." (A1) }\end{array}$ & $\begin{array}{l}\text { "the positive side to it is in } \\
\text { circumstances in which you might } \\
\text { feel a bit lonely, you feel you've got } \\
\text { a bit of a comfort around you with } \\
\text { these things which aren't really } \\
\text { people." (N9) }\end{array}$ \\
\hline & & $\begin{array}{l}\text { "I still think he (teddy bear) makes me } \\
\text { feel safe, and also I think it's like } \\
\text { this consistency, there is something } \\
\text { from home with me that I'm very } \\
\text { attached to, that might make things } \\
\text { better." (A4) }\end{array}$ & $\begin{array}{l}\text { "I had this really great tree, she had } \\
\text { great hair-so that's foliage, it was } \\
\text { comforting to sit by, and there was a } \\
\text { very good associated feeling. I could } \\
\text { lie there for hours and look up, I } \\
\text { enjoyed reading and drawing by her, } \\
\text { and playing with my dolls by her ... } \\
\text { I was just constantly fascinated by } \\
\text { her, and so, as crazy as it sounds, I } \\
\text { had a good relationship with her. I } \\
\text { was quite happy to see her and she } \\
\text { was quite happy to see me. She was } \\
\text { like a guardian. I didn't mind being } \\
\text { alone with her, I felt protected, safe } \\
\text { and happy." (N14) }\end{array}$ \\
\hline $\begin{array}{l}\text { Greater affinity } \\
\text { for objects } \\
\text { than people }\end{array}$ & & $\begin{array}{l}\text { "I just remember feeling more } \\
\text { comfortable with objects than with } \\
\text { people, like I could trust them more, } \\
\text { as if they were more honest." (A5) }\end{array}$ & $\begin{array}{l}\text { "Sometimes maybe I feel more sorry } \\
\text { for objects than I do about people. } \\
\text { But I think that's because maybe I } \\
\text { feel that people can stick up for } \\
\text { themselves more, whereas objects } \\
\text { are entirely dependent on me, and } \\
\text { can't speak or move." (N12) }\end{array}$ \\
\hline \multirow[t]{2}{*}{$\begin{array}{l}\text { Upsetting or } \\
\quad \text { distressing } \\
\text { experiences }\end{array}$} & \multirow[t]{2}{*}{$\begin{array}{l}\text { Worrying } \\
\text { about } \\
\text { agents }\end{array}$} & $\begin{array}{l}\text { "I was at secondary school, so it must } \\
\text { have been around } 14 \text {. I didn't like to } \\
\text { throw things away unless I was at } \\
\text { home, because I felt like the rubbish } \\
\text { would be lonely, as if it had feelings, } \\
\text { like it had to be thrown away at } \\
\text { home. I liked to throw things away } \\
\text { in pairs, again so it kind of wasn't on } \\
\text { its own." (A3) }\end{array}$ & $\begin{array}{l}\text { "Like even cutlery, just sort of } \\
\text { thinking that you can't have one } \\
\text { piece on their own because it could } \\
\text { be lonely." (N11) }\end{array}$ \\
\hline & & $\begin{array}{l}\text { "I almost feel sorry for objects I dislike, } \\
\text { I feel guilty for that. Like I have this } \\
\text { guitar that I can't really touch because } \\
\text { I am hypersensitive to the material } \\
\text { that it's made of, and I feel guilty for } \\
\text { having had to hide it, because just } \\
\text { thinking about its texture would make } \\
\text { me shiver. And I always feel guilty } \\
\text { when I remember it's hidden away, } \\
\text { like I've locked it up." (A5) }\end{array}$ & $\begin{array}{l}\text { "Sometimes I feel guilty about } \\
\text { complaining about inanimate objects } \\
\text { because I feel like they can hear me. } \\
\text { For instance, I was recently } \\
\text { complaining that my pillow was } \\
\text { uncomfortable, but I would kind of } \\
\text { feel guilty if I would say that in the } \\
\text { pillow's presence." (N12) }\end{array}$ \\
\hline
\end{tabular}


TABle 1. (CONTINUED)

\begin{tabular}{|c|c|c|c|}
\hline \multirow[b]{2}{*}{ Themes } & \multirow[b]{2}{*}{ Subthemes } & \multicolumn{2}{|c|}{ Example quotes } \\
\hline & & Autistic & Nonautistic \\
\hline & $\begin{array}{l}\text { Deliberate } \\
\quad \text { malfunction }\end{array}$ & $\begin{array}{l}\text { "Sometimes at school I would think } \\
\text { the computers would deliberately go } \\
\text { off just too annoying me, to make } \\
\text { me say 'oh why everyone else's is } \\
\text { working but not mine?' a sort of } \\
\text { sense of being picked on." (A1) }\end{array}$ & $\begin{array}{l}\text { "It's not that I believe the computer is } \\
\text { capable of responding automatically, } \\
\text { but sometimes that's where the } \\
\text { thought would be triggered, that the } \\
\text { computer has its own thoughts and } \\
\text { feelings that might be deliberately, } \\
\text { getting in the way, or playing up." } \\
\text { (N14) }\end{array}$ \\
\hline $\begin{array}{l}\text { Supporting autistic } \\
\text { challenges }\end{array}$ & & $\begin{array}{l}\text { "I think it's definitely a positive thing } \\
\text { in my life, and we were able to use } \\
\text { some of my toys to teach me more } \\
\text { about being friends and caring and } \\
\text { things like that, in a way I could } \\
\text { understand and that was not } \\
\text { threatening. I think that while we } \\
\text { didn't know about the Asperger's, } \\
\text { that's one of the things that my } \\
\text { family got right, almost by accident. } \\
\text { I think I's a really good thing. With } \\
\text { my son, we use his toys to help him } \\
\text { make sense of the world, and asking } \\
\text { him 'how do you think that would } \\
\text { make a certain toy feel?' and 'how a } \\
\text { certain toy feels about this?' and } \\
\text { getting him to think about feelings. } \\
\text { Because they weren't people, I think } \\
\text { it was easier for him and less } \\
\text { difficult to deal with them first, and } \\
\text { then start applying that to people." } \\
\text { (A7) } \\
\text { "I think it helped me feel safe, because } \\
\text { I couldn't communicate properly } \\
\text { with people and I would use my } \\
\text { teddy to communicate, not with } \\
\text { other people but I will tell him } \\
\text { things that I couldn't tell other } \\
\text { people, like when you're going to } \\
\text { bed and you replaying your day, I } \\
\text { will talk to him and get all of that } \\
\text { out." (A4) }\end{array}$ & \\
\hline $\begin{array}{l}\text { What other } \\
\text { people } \\
\text { may think }\end{array}$ & & $\begin{array}{l}\text { "I'm aware that I do it sometimes, but } \\
\text { I'm not always aware of whether I } \\
\text { do it or not, so sometimes it's when } \\
\text { people are laughing at me that I } \\
\text { realise that I've done it without } \\
\text { meaning to." (A4) }\end{array}$ & $\begin{array}{l}\text { "If it's with animals I think it's } \\
\text { different, because a lot of people do } \\
\text { that. It's one thing to ask your cat } \\
\text { how was his day in front of other } \\
\text { people versus asking your cooking } \\
\text { utensils are you ready to cook some } \\
\text { amazing dinner with other people } \\
\text { watching you and looking at you } \\
\text { like you're absolutely insane."' } \\
\text { (N10) }\end{array}$ \\
\hline
\end{tabular}

Themes identified in both autistic and nonautistic interviews are italicized.

the phases defined by Braun and Clarke ${ }^{29}$ : (1) familiarization with the data, (2) generation of initial codes, (3) search for themes, (4) review of themes, (5) definition and naming of themes, and (6) production of the report. The researcher applied an inductive coding approach to all interviews before collapsing together the emergent codes into themes and comparing across groups. Researcher O.N. first analyzed the interview data, followed by A.R. A.R. and O.N. conferred several times during the coding process to review areas of divergence and decide on final themes and subthemes. R.C.W. confirmed agreement with the final set of quotes and themes. The researchers are nonautistic, and two have a tendency to anthropomorphize, therefore sharing participants' perspectives to a certain degree. Themes from the two groups (autistic and nonautistic) have been reported together due to the extent of overlap. 


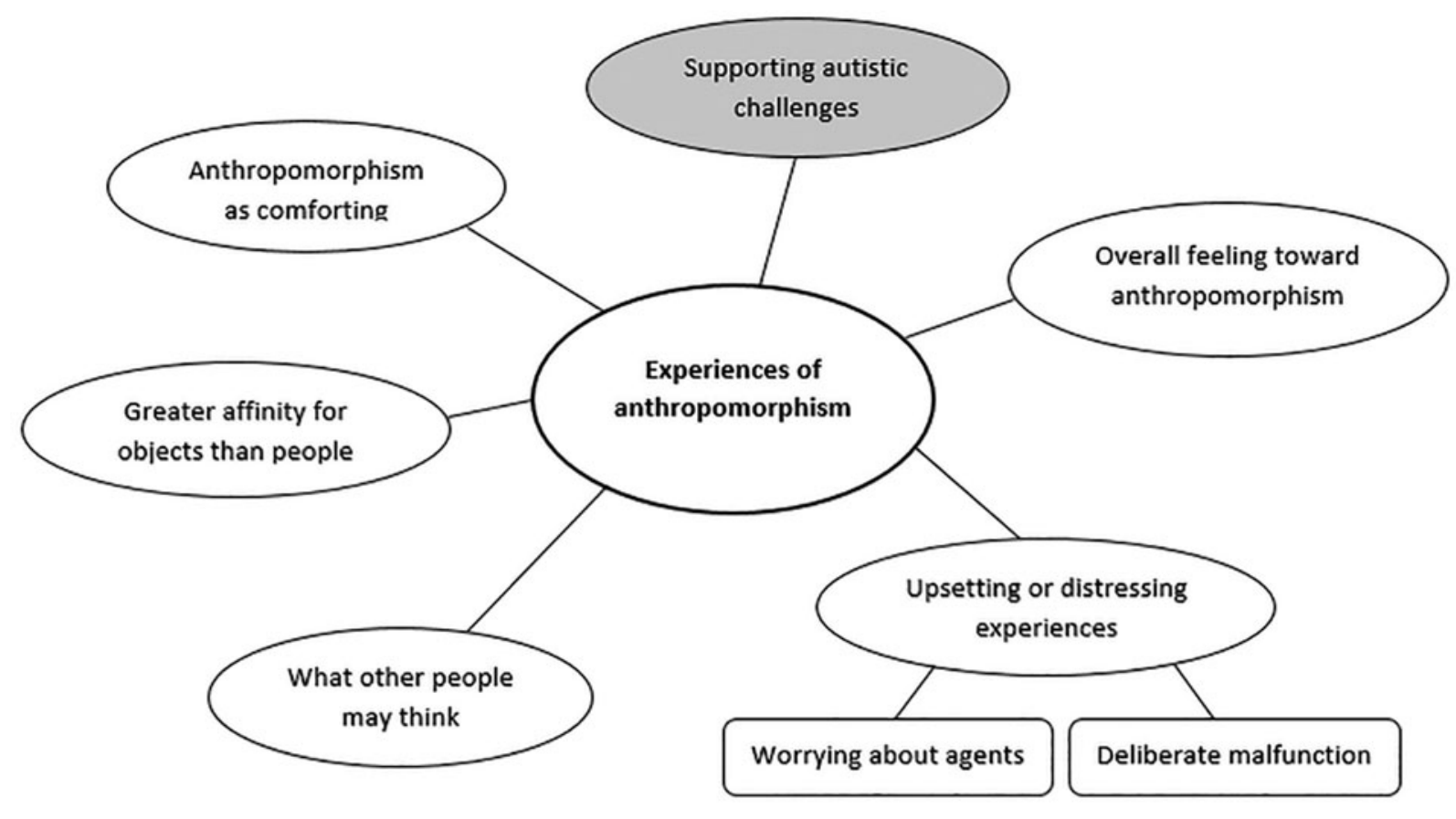

FIG. 1. Thematic map.

\section{Results}

Participants in both groups anthropomorphized animals, vehicles, soft toys, trees, technological devices, household objects, buildings, musical instruments, fruit, and more. The types of attributions that participants mentioned included different emotions, gender, personality, free will and intentions, and the ability to understand speech. Researchers identified five main themes across both groups, with an additional theme exclusive to the autistic group (Table 1 and Fig. 1).

Participants in both groups spontaneously mentioned that they were aware of the fact that, with the exception of animals/pets, the objects they anthropomorphized did not necessarily have the capacity to think or feel. As such, unlike for pathological symptoms (such as delusions), ${ }^{30}$ anthropomorphic experiences described by participants in the current study were accompanied by insight that, in reality, anthropomorphized agents likely lack the capacity to think/feel.

Almost all participants experienced the tendency to anthropomorphize as mostly or entirely automatic. This was the case for both autistic ("It just happens, it's not something I try to do or anything" A3) and nonautistic ("I think it happens automatically" N9) individuals. Most participants mentioned that anthropomorphism had become less frequent and less intense as they grew older ("I think when I was younger it was more automatic, I applied it to a lot of things that had sentimental value to me" N10), although some of their childhood anthropomorphic tendencies persisted in adulthood ("I think it's faded and became a lot less real. Although I would still struggle to destroy some objects" A5). Regarding a possible link between personal experience and the content of anthropomorphic attributions, replies in both groups were mixed; some participants stated that they could clearly see a connection and thought of it as a form of projection ("I did kind of give feelings to the car, as if it would be sad I was getting rid of it, but I guess projecting my own feelings into the car" A3), whereas others felt that it served an emotion-regulation purpose ("I actually think sometimes it was the opposite, if I was feeling sad attributing positive things to things would make me feel better, kind of like therapeutic" N15) or that attributions depended on the characteristics of the agents ("How I feel about an object will depend on the object and the context" A5). Similarly, some participants indicated that their anthropomorphic tendencies were stronger with personally significant agents, and others felt that the tendencies did not depend on their personal preference. Several participants in both groups indicated that pareidolia (the phenomenon in which one perceives a pattern resembling a face in inanimate objects) ${ }^{31}$ often induced anthropomorphism.

\section{Overall feelings toward anthropomorphism}

When asked about their overall feelings toward anthropomorphism, participants in each group differed as to whether they described the overall experience as neutral, positive, or negative. Some participants (A1, A4, A5, N11, N13, and N14) described their anthropomorphic experiences as neutral:

It's just something I do, I don't attach a particular connotation to it. (A1) 
I think it's just there, a part of how my brain sees things. I don't think it's a bad thing or a good thing. (N14)

Other participants (A2, A6, A7, N9, N10, N15, and N16) had positive views and considered their anthropomorphism to be a beneficial addition to their life and perception:

I think that it's amusing, it's fun. For example, if the teddy bear is in the room and I'm alone in my flat, I don't feel like I'm alone because the teddy bear is there. (A2)

On the whole, it's a positive experience. It's something that gives me a feeling of purpose in life, of oneness. If I didn't feel this way about things, I think I would feel it's a loss, I would feel life had less point to it, less value. (N9)

Conversely, three participants (A3, A8, and N12) viewed their overall experience as more negative, a view that seemed to strongly relate to the automatic and uncontrollable aspect of anthropomorphism:

It's mostly a negative thing. I think it's really tiring, because everything just seems to be sort of radiating with emotion-the light switch, or the tap, or water coming out of the tap-it's just literally everything. And I've been trying to get to the bottom of it for years, because I think it's something I was born with, and it's a really big part of my life, almost a disability in itself. It's not just a sort of quirky personality trait, it actually has some really detrimental effects on everyday living. (A8)

\section{Anthropomorphism as comforting}

The most prevalent theme in both groups (A1, A2, A3, A4, A5, A6, A7, N9, N10, N11, N13, N14, N15, and N16) was that of anthropomorphism as promoting a sense of comfort and safety during childhood and into adulthood. Examples of comforting anthropomorphic experiences were even mentioned by some of the participants who described their overall experience as neutral or more negative. Participants described anthropomorphism as a pleasant experience that induced a sense of well-being:

I definitely personify clothes, like I feel coats and stuff like that have a personality. I have a coat that I got a few years ago, and it's comforting, it makes me feel healthy when I'm unwell. I can't explain why, it's not rational, it just makes me feel that way. (A5)

Such experiences were often accompanied by a sense of social presence related to the character of the agents:

I don't mind being by myself, but it is comforting to be around objects sometimes because they are imbued with the ability to be comforting in a way, because they have more personality. (N16)

These type of comforting experiences seemed to often be associated with a feeling of being protected:

I think I was quite easily comforted by toys and familiar objects, so it was almost like they were protectors. (A6)

Participants frequently compared the presence of anthropomorphized agents to that of friends. As one participant explained:
It's a similar feeling to having a sense of community, the feeling that you're living in a place where you know the locals and your neighbours look out for you and they're also your friends, it is as if the objects around you are your friends and you're looking out for them and they're somehow looking out for you. (N9)

\section{Greater affinity for objects than people}

Anthropomorphic experiences led some participants, both autistic and nonautistic (A5, A7, N9, and N12), to report feeling more affinity for anthropomorphized agents than for people:

I just remember feeling more comfortable with objects than with people, like I could trust them more, as if they were more honest. (A5)

The whole process sometimes puts me in the position where I feel I'm on the side of the objects against other people, like they're my gang or my friends, and someone else, a human being, is not, or vice versa. I feel like I have these objects and I'm protective of them against people. (N9)

\section{Supporting autistic challenges}

Nearly all autistic participants viewed their anthropomorphism as a way of supporting some of the challenges they encountered due to being on the autistic spectrum. Most participants in the autistic group (A1, A2, A4, A5, A6, and A7) explained that sometimes, especially when they were growing up, anthropomorphism served as a safe and comforting alternative that allowed them to feel socially connected when human interaction felt inaccessible, or was unavailable:

People can be a bit uncomfortable ... and people are usually quite ambiguous, like with irony and stuff, they can say things which they don't mean ... it is very confusing, but animals and trees, they don't do that. (A6)

Others felt that by allowing a more comfortable interaction, anthropomorphism supported their self-regulation, either emotional or sensory:

It's definitely taught me how to comfort myself if I'm sad or alone. (A2)

I think I found people a lot harder for an awful lot of years. It wasn't until somewhere in my 30's that I really began to be comfortable with other humans, and to be able to do better. I had to cope with the fact that I take in for more detailed information than a lot of people do, so sometimes I would just get flooded and overwhelmed, there was just too much information, and I think that my cat is really good at not bombarding me with massive information, and now with my partner we can just go someplace else that's quiet if there are just too many people and noise around. (A7)

Participants also described how anthropomorphizing enabled them to further develop an understanding of their own emotions, and through that, allowed a safer path into learning and understanding social communications and relations:

I know it made me anxious as a child, and I have learned some things about myself, but I suppose because I have issues with dealing with emotions anyway, and relationship stuff, that perhaps it's helped me to process those things. (A3) 
Furthermore, reflecting on the role of anthropomorphism in their childhood, several participants in the autistic group (and one in the nonautistic group) mentioned time spent in solitude, loneliness, and social exclusion:

School usually ended early, so I would be alone so long before my parents came home. And my friends all lived quite far away from me, I was alone. (A6)

I think I was nurtured plenty, but I was lonely, definitely very lonely. (A2)

I was very very lonely as a child, I didn't have many friends, between the lack of being able to do anything sport based because of the injuries, and the Asperger's that we didn't know anything about, I really didn't fit in. (A7)

\section{Upsetting or distressing experiences}

Two main themes emerged in which anthropomorphic tendencies were described in terms of a negative, upsetting, or unpleasant experience to various degrees: worrying about anthropomorphized agents, and feeling an anthropomorphized agent may be malfunctioning intentionally.

Worrying about anthropomorphized agents. The experience of concern for anthropomorphized agents was highly prevalent among participants in both groups (A2, A3, A4, A5, A6, A7, A8, N9, N11, N12, N14, N15, and N16), and frequently focused upon the possibility of an agent feeling lonely, abandoned, unwanted, or left out, and were often described as triggering feelings of sadness or guilt:

My stuffed animals were and still are kept on a high shelf in the closet, and often I'd feel pretty guilty about that, but then I would also catch myself and think well, they're not alive, so that was part of maturing, realising that. But I still feel a little bit guilty, even now I still feel the same way about those objects. (N16)

These feelings were not limited to participants' own possessions, with one explaining that:

Going shopping, for example, is really difficult. When I go to the superstore and there's tons and tons of objects on the shelf, I should be able to enjoy looking at all the things, but I feel sorry for this object because it's not as expensive as the other one, or the one that looks better than another one, so I feel sorry for the other one, and I get so overwhelmed by their stuff that I end up making not great decisions about what to buy ... it's a really terrible thing. (A8)

Two nonautistic participants (N11 and N12) and two autistic participants ( $\mathrm{A} 3$ and $\mathrm{A} 8$ ) indicated that their experiences of anthropomorphism were mostly or solely based on these types of upsetting emotional attributions. Such attributions commonly relate to the individual's intentions, actions, or speech affecting the agent. Three of these four participants had a past or present diagnosis of OCD and identified that the negative content of their anthropomorphic attributions led to distressing emotions, similar to those associated with their experience of OCD symptoms, such as anxiety and sadness:

I think it was related to OCD, because it's the same kind of feeling of anxiety. (A3)
It's almost like everything reflects sadness back to you. So it's Sadness, but this is where it seems to maybe overlap with OCD I think, and the autism I mean, I think they all overlap a bit. (A8)

In these cases, it seems difficult to control anthropomorphism that played a key role in their distress and led to attempts to regain control by performing actions to regulate their stress (e.g., throwing items away in pairs). As one participant explained:

To the extent of the control piece that comes with OCD, it was kind of projecting my own fears on to the objects, trying to control them in that sense, to prevent things ... So I suppose there is a bit of interplay there. (N11)

One autistic participant's (A8) anthropomorphism was distressing to the point that they sought professional counseling to help understand and manage such experiences.

Deliberate malfunction. The second theme associated with negative feelings toward anthropomorphism relates to the category of mechanical or technological devices, and to situations in which they fail to work properly. Half of the participants in each group (A1, A2, A4, A6, N10, N12, N13, and N14) indicated that these situations tended to result in the view that the agent was intentionally undermining the individual, leading to feelings of irritation, anger, or frustration:

The car, and also I.T. things, like computers, it's more when they're not working, I kind of think that they're doing it on purpose to piss me off, that's how I feel. (A4)

Some of the participants associated this type of experience with their own mental or emotional state:

Maybe in a negative mood, when I'm having a really bad day I would tend to think everything is conspiring against me, like the cord was there specifically to trip me, like it's doing it on purpose just to get me angry. (A2)

Perhaps if I don't get my way with those things, I look at either the video game or the system that runs the game as something that colluded against me to tick me off and to anger me purposely, just doing what it wants to annoy me. (N10)

\section{What other people may think}

Participants in both groups (A3, A4, A6, N9, N10, N13, and N15) indicated that they felt that their anthropomorphic tendencies might be perceived negatively by others:

My boyfriend knows that I do it, it's quite a natural thing, but in front of people I didn't know very well I might be worried about what they were thinking about me doing it, they would think it was abnormal or a bit strange. (N15)

For those whose anthropomorphism triggered certain behaviors, there was also an attempt to hide their active engagement with anthropomorphized agents:

I remember kind of trying to hide it ... I remember being embarrassed and ashamed when I got to teenage years. I think 
I knew that it wasn't kind of normal behaviour, so I was embarrassed in case someone saw me doing it, or realised what I was doing. (A3)

\section{Discussion}

This study examined the lived experiences of anthropomorphism in a group of autistic and nonautistic individuals. The findings build on results from a recent study that found a high proportion of autistic individuals anthropomorphize inanimate objects. $^{2}$

Those who spoke to us had mixed views regarding whether the phenomenon was positive, neutral, or negative. Participants in both groups explained that they not only derived comfort from their personal relationship with nonhuman agents but also worried about their well-being - which for some, could lead to great distress. Such views appear to be complex, since they are not based on a single type of experience; in most cases, participants with an overall positive view also described some negative experiences, and vice versa. The autistic individuals acknowledged that anthropomorphism often supported some of the challenges they experienced (e.g., understanding emotions and relationships).

Autistic and nonautistic participants reported similar experiences of anthropomorphism. This was intriguing for a number of reasons. First, anthropomorphism in the general population has been postulated to be an expression of enhanced motivation to connect with others, yet autistic individuals' social motivation has been hypothesized to be reduced. ${ }^{12,13}$ As such, we sought to explore whether the nature of anthropomorphism might be different for autistic and nonautistic people. Results from the current study suggest otherwise, with autistic individuals describing their relationships with different nonhuman agents as meaningful experiences, which supported their need for social connectedness. This may suggest that social interest and motivation in autism should not be considered as diminished, but perhaps as less constrained to human entities. This is in keeping with recent research that challenges assumptions about social motivation in autism by highlighting that autistic people's external social behaviors might appear different, but this does not equate to a diminished tendency to seek social interaction. $^{32,33}$

Second, previous research has linked autism to difficulties with mentalizing, but traditionally, this difference was framed as a reduced (or even absent) ability to understand that others have thoughts and feelings, which may differ from one's own. ${ }^{34,35}$ And yet, the accounts given by participants in the current study reveal many examples of mentalizing: the attribution of emotions, mental states, and personality traits to different nonhuman agents. This may be in line with Brosnan et al.'s study, ${ }^{36}$ in which autistic adolescents showed better performance when identifying emotion in cartoon faces compared with human faces. It should be stressed that for most, an interaction with nonhuman agents was not mentioned as necessarily preferable, but as an alternative that was nonthreatening and provided a sense of social connectedness. Other studies similarly support participants' views regarding the ease of interaction with nonhuman agents, showing that the use of nonhuman agents was associated with improved performance in autistic adults on mentalizing tasks, ${ }^{37}$ and in autistic children on imitation ${ }^{38}$ and joint attention ${ }^{39}$ inter- ventions. Interaction with nonhuman agents may be experienced as more comfortable compared with human interaction due to various reasons, such as their level of predictability, ${ }^{1}$ controllability, and lower social and sensory complexity. ${ }^{20}$

Third, participants in both groups described experiencing concern and feelings of sympathy and empathy toward agents, in line with previous studies indicating that anthropomorphism predicts moral concern for anthropomorphized agents. ${ }^{12,13}$ Previous accounts have proposed that autistic individuals are lacking in cognitive empathy, ${ }^{40}$ possibly due to poor introspective ability and a lack of self-other distinction, ${ }^{41}$ yet autistic participants in the current study described extensive empathic responses to nonhuman agents. More recent discussions of empathy, however, point to a lack of conceptual and empirical distinction between socio-cognitive constructs, such as empathy and mentalizing within the literature, ${ }^{42}$ and raise the possibility_-and resulting damageof misinterpretation of autistic behavior and understanding by nonautistic individuals. ${ }^{33,43,44}$

The anthropomorphism experienced by most participants does not seem to be a form of social synesthesia, insofar as 15 participants did not find that their specific anthropomorphic associations were consistent across time. Only one participant (N16) reported that the attributions were highly stable (i.e., all objects elicited the same attributions over time).

The autistic participants in our study raised the value of anthropomorphism as a possible stepping-stone to better understanding their own emotions and interacting with other people. Given that these abilities can prove challenging for those on the autistic spectrum, mentalizing using anthropomorphized agents (even for those who do not spontaneously anthropomorphize) may serve to improve emotional awareness and social skills in autism. Such potential is demonstrated by an intervention study by Golan et al. ${ }^{45}$ in which autistic children (aged 4-7 years) showed significantly improved performance in emotion recognition of human faces following an intervention that included anthropomorphized agents with human faces. In addition, as noted by participants in the current study, unlike interaction with nonhuman agents, human interaction may be experienced as stressful for individuals on the spectrum. This highlights the importance of nonhuman agents in providing a comfortable alternative that may alleviate stress and therefore enable a safer path to exploring and further developing social skills. ${ }^{20}$ Indeed, research has suggested that object attachment is a compensatory strategy used when human others are perceived as unreliable or unavailable. ${ }^{46}$

While embracing the potential value of anthropomorphism, we are also mindful of the negative aspects. Upsetting experiences (to various degrees) were common among participants in both groups, and for four individuals, worries about anthropomorphized agents were the most salient aspect of anthropomorphic experiences. Three of these individuals had a past/present diagnosis of OCD and described greater distress in such situations, as well as feeling compelled to act in a way that would ease their stress (e.g., throwing items in pairs so they wouldn't be lonely). Anthropomorphism has been linked with emotional attachment to objects and hoarding behaviors (which are common in OCD) in clinical and nonclinical samples, ${ }^{47,48}$ and the current findings add support to this association. The potential for distress caused by anthropomorphism highlights the importance of further 
research aimed at investigating how best to support individuals for whom anthropomorphism negatively affects mental well-being.

While the findings offer an insight into social cognition for autistic and nonautistic adults, the sample size in the current study was relatively small, and as such should be followed up by larger scale studies on this topic. Additionally, subsequent research should directly explore the link between anthropomorphism and factors such as mentalizing ability, loneliness, and social connectedness to build on the self-report approach taken in the current study.

In conclusion, although many factors thought to play a central role in anthropomorphism are considered to be atypical in autism, the anthropomorphic experiences of autistic and nonautistic participants were found to be generally similar. Participants in both groups described anthropomorphism as eliciting a sense of friendship and closeness. The autistic participants additionally highlighted the specific importance of such experiences to individuals on the spectrum: nonhuman anthropomorphized agents serve as a nonthreatening comforting alternative to human interactions when these are unavailable or pose socioemotional and/or sensory difficulties.

\section{Acknowledgment}

The authors wish to thank Jana Brinkert for her contribution to the study.

\section{Disclaimer}

This article has been submitted solely to this Journal and is not published, in press, or submitted elsewhere.

\section{Authorship Confirmation Statement}

A.R. and R.C.W. developed the study concept, and all authors contributed to the study design. Participant recruitment, data collection, and analysis were performed by O.N. O.N. drafted the article, and A.R. and R.C.W. provided critical revisions. All co-authors have reviewed and approved the article prior to submission.

\section{Author Disclosure Statement}

No competing financial interests exist.

\section{Funding Information}

No funding was attached to the project.

\section{References}

1. Waytz A, Cacioppo J, Epley N. Who sees human? The stability and importance of individual differences in anthropomorphism. Perspect Psychol Sci. 2010;5(3):219-232.

2. White RC, Remington A. Object personification in autism: This paper will be very sad if you don't read it. Autism. 2019;23(4):1042-1045.

3. Salvin S. I have felt sympathy for objects since I was a very young child. Autism: Feeling sympathy for inanimate objects [Blog post]. June 29, 2015. http://adultswith autism.org.uk/autism-feeling-sympathy-for-objects (accessed October 10, 2019).
4. Mukhopadhyay T. How Can I Talk If My Lips Don't Move? New York, NY: Arcade; 2008.

5. Walkinfaith925. My autistic traits: Personification [Blog post]. July 21, 2015. https://autismalifetimeundiagnosed. wordpress.com/2015/07/21/my-autistic-traits-personification (accessed April 14, 2019).

6. Wrong Planet. Personifying objects [Internet forum]. 2009. http://wrongplanet.net/forums/viewtopic.php?t=112763\& postdays $=0 \&$ postorder $=$ asc $\&$ start $=0$ (accessed March 24, 2019).

7. American Psychiatric Association. Diagnostic and Statistical Manual of Mental Disorders (5th ed.). Washington, DC: American Psychiatric Association; 2013.

8. Baron-Cohen S. Theory of mind and autism: A review. Int Rev Res Mental Retard. 2000;23:169-184.

9. Klin A. Attributing social meaning to ambiguous visual stimuli in higher-functioning autism and Asperger syndrome: The social attribution task. J Child Psychol Psychiatry. 2000; 41(7):831-846.

10. Castelli F, Frith C, Happe F, Frith U. Autism, Asperger syndrome and brain mechanisms for the attribution of mental states to animated shapes. Brain. 2002;125(8):1839-1849.

11. Chevallier C, Kohls G, Troiani V, Brodkin ES, Schultz RT. The social motivation theory of autism. Trends Cogn Sci. 2012;16(4):231-239.

12. Epley N, Waytz A, Akalis S, Cacioppo JT. When we need a human: Motivational determinants of anthropomorphism. Soc Cogn. 2008;26(2):143-155.

13. Epley N, Schroeder J, Waytz A. Motivated mind perception: Treating pets as people and people as animals. In: Gervais SJ, ed. Objectification and (De) Humanization. New York, NY: Springer; 2013;127-152.

14. Bauminger N, Kasari C. Loneliness and friendship in highfunctioning children with autism. Child Dev. 2000;71(2): 447-456.

15. Ee D, Hwang YI, Reppermund S, et al. Loneliness in adults on the autism spectrum. Autism Adulth. 2019;1(3): 182-193.

16. Mazurek MO. Loneliness, friendship, and well-being in adults with autism spectrum disorders. Autism. 2014;18(3): 223-332.

17. Boulter C, Freeston M, South M, Rodgers J. Intolerance of uncertainty as a framework for understanding anxiety in children and adolescents with autism spectrum disorders. $J$ Autism Dev Disord. 2014;44(6):1391-1402.

18. Neil L, Olsson NC, Pellicano E. The relationship between intolerance of uncertainty, sensory sensitivities, and anxiety in autistic and typically developing children. J Autism Dev Disord. 2016;46(6):1962-1973.

19. Pellicano E, Burr, D. When the world becomes 'too real': A Bayesian explanation of autistic perception. Trends Cogn Sci. 2012;16(10):504-510.

20. Atherton G, Cross L. Seeing more than human: Autism and anthropomorphic theory of mind. Front Psychol. 2018;9:528.

21. Simner J, Holenstein E. Ordinal linguistic personification as a variant of synesthesia. J Cogn Neurosci. 2007;19(4): 694-703.

22. Smilek D, Malcolmson KA, Carriere JS, Eller M, Kwan D, Reynolds M. When " 3 " is a Jerk and " $E$ " is a king: Personifying inanimate objects in synesthesia. J Cogn Neurosci. 2007;19(6):981-992.

23. Amin M, Olu-Lafe O, Claessen LE, -et al. Understanding grapheme personification: A social synaesthesia? J Neuropsychol. 2011;5(2):255-282. 
24. Sobczak-Edmans M. A systematic study of personification in synaesthesia: Behavioural and neuroimaging studies [Doctoral dissertation]. United Kingdom: Department of Psychology, Brunel University; 2013.

25. Cullen H, Kanai R, Bahrami B, Rees G. Individual differences in anthropomorphic attributions and human brain structure. Soc Cogn Affect Neurosci. 2013;9(9):1276-1280.

26. Baron-Cohen $\mathrm{S}$, Johnson $\mathrm{D}$, Asher J, et al. Is synaesthesia more common in autism? Mol Autism. 2013;4(1):40.

27. Neufeld J, Roy M, Zapf A, et al. Is synesthesia more common in patients with Asperger syndrome? Front Hum Neurosci. 2013;7:847.

28. Hughes JE, Simner J, Baron-Cohen S, Treffert DA, Ward J. Is synaesthesia more prevalent in autism spectrum conditions? Only where there is prodigious talent. Multisens Res. 2017;30(3-5):391-408.

29. Braun V, Clarke V. Using thematic analysis in psychology. Qual Res Psychol. 2006;3(2):77-101.

30. World Health Organization. International Statistical Classification of Diseases and Related Health Problems (10th Rev., Vols. I-III). Geneva, Switzerland: World Health Organization; 2015.

31. Liu J, Li J, Feng L, Li L, Tian J, Lee K. Seeing Jesus in toast: Neural and behavioral correlates of face pareidolia. Cortex. 2014;53:60-77.

32. Jaswal VK, Akhtar N. Being vs. appearing socially uninterested: Challenging assumptions about social motivation in autism. Behav Brain Sci. 2018;1-84.

33. Legault M, Bourdon JN, Poirier P. Neurocognitive variety in neurotypical environments: The source of "deficit" in autism. J Behav Brain Sci. 2019;9:246-272.

34. Senju A, Southgate V, White S, Frith U. Mindblind eyes: An absence of spontaneous theory of mind in Asperger syndrome. Science. 2009;325(5942):883-885.

35. Frith U. Mind blindness and the brain in autism. Neuron. 2001;32(6):969-979.

36. Brosnan M, Johnson H, Grawmeyer B, Chapman E, Benton L. Emotion recognition in animated compared to human stimuli in adolescents with autism spectrum disorder. $J$ Autism Dev Disord. 2015;45(6):1785-1796.

37. Atherton G, Cross L. Animal Faux Pas: Two legs good four legs bad for theory of mind, but not in the broad autism spectrum. J Genet Psychol. 2019:1-15.

38. Warren Z, Zheng Z, Das S, et al. Brief report: Development of a robotic intervention platform for young children with ASD. J Autism Dev Disord. 2015;45(12):3870-3876.
39. Kumazaki, H, Yoshikawa Y, Yoshimura Y, et al. The impact of robotic intervention on joint attention in children with autism spectrum disorders. Mol Autism. 2018; 9(1):46.

40. Baron-Cohen S, Wheelwright S. The empathy quotient: An investigation of adults with Asperger syndrome or high functioning autism, and normal sex differences. J Autism Dev Disord. 2004;34(2):163-175.

41. Lombardo MV, Baron-Cohen S. The role of the self in mindblindness in autism. Conscious Cogn. 2011;20(1):130-140.

42. Happé F, Cook JL, Bird G. The structure of social cognition: In (ter) dependence of sociocognitive processes. Аnnu Rev Psychol. 2017;68:243-267.

43. Milton, DEM, Heasman B, Sheppard E. Double empathy. In: F. Volkmar (ed). Encyclopedia of Autism Spectrum Disorders. New York, NY: Springer; 2018;1-8.

44. Nicolaidis C, Milton D, Sasson NJ, Sheppard E, Yergeau M. An expert discussion on autism and empathy. Autism Adulth. 2018;1(1):4-11.

45. Golan O, Ashwin E, Granader Y, et al. Enhancing emotion recognition in children with autism spectrum conditions: An intervention using animated vehicles with real emotional faces. J Autism Dev Disord. 2010;40(3):269-279.

46. Keefer LA, Landau MJ, Rothschild, ZK, Sullivan D. Attachment to objects as compensation for close others' perceived unreliability. J Exp Soc Psychol. 2012;48(4): 912-917.

47. Neave N, Tyson H, McInnes L, Hamilton C. The role of attachment style and anthropomorphism in predicting hoarding behaviours in a non-clinical sample. Pers Individ Dif. 2016;99:33-37.

48. Yap K, Grisham JR. Unpacking the construct of emotional attachment to objects and its association with hoarding symptoms. J Behav Addict. 2019;8:249-258.

Address correspondence to: Orli Negri, $M S c$

Centre for Research in Autism and Education (CRAE)

UCL Institute of Education 55-59 Gordon Square Bloomsbury

London WC1H ONU United Kingdom

Email: o.negri.16@ucl.ac.uk 